\section{Optimization of process variables for preparation of pomegranate juice-fortified aonla candy}

\author{
Vijay Singh Meena ${ }^{1}$, Kirti Jalgaonkar ${ }^{2}$, \\ Manoj Kumar Mahawar ${ }^{2, *}$, Bharat Bhushan ${ }^{1}$, \\ Bhushan Bibwe $^{2}$ and Poonam Kashyup ${ }^{3}$ \\ ${ }^{1}$ ICAR-National Bureau of Plant Genetic Resource, \\ New Delhi 110 012, India \\ ${ }^{2}$ ICAR-Central Institute of Post-Harvest Engineering and Technology, \\ Abohar 152 116, India \\ ${ }^{3}$ ICAR-Indian Institute of Farming Systems Research, \\ Meerut 110 012, India
}

This study was aimed to evaluate the effect of sugar syrup concentration (SSC) $\left(0,30\right.$ and $60{ }^{\circ}$ Brix $\left.\left({ }^{\circ} \mathrm{B}\right)\right)$, time of dipping (TD) of aonla segments in pomegranate juice (30, 60 and $90 \mathrm{~min}$ ) and drying temperature (DT) $\left(50^{\circ} \mathrm{C}, 60^{\circ} \mathrm{C}\right.$ and $\left.70^{\circ} \mathrm{C}\right)$ on the quality of aonla candy. The prepared candy was assessed for its physical, chemical and sensorial characteristics such as total soluble solids (TSS), titratable acidity (TA), ascorbic acid content (AA) and overall acceptability (OAA). Response surface methodology using Box-Behnken design was utilized for formulating the design of experiments, statistical analysis and optimization of process variables. Second-order polynomial models were fitted to determine the responses as a function of process variables. All three independent variables were observed to have significant effect $(P \leq 0.01)$ with coefficient of determination $\left(R^{2} \geq 0.90\right)$. The optimum process conditions for preparation of novel aonla candy were SSC of $60^{\circ} \mathrm{B}$, TD of $30 \mathrm{~min}$ and DT of $7^{\circ} \mathrm{C}$. The quality characteristics recorded at optimum experimental condition were TSS of $30.16^{\circ} \mathrm{B}$, AA of $207.79 \mathrm{mg} / 100 \mathrm{~g}$ and OAA of 7.71 with lower TA of $1.48 \%$.

Keywords: Aonla candy, pomegranate juice, process variables optimization, response surface methodology,

AONLA or Indian gooseberry (Emblica officinalis Gaertn.) is a potential gift of nature to mankind. The semi-arid and arid regions contribute towards ample production of aonla in the country. The fruit is grown commercially because of high economic returns, medicinal and nutraceutical value $^{1,2}$. It is suitable for marginal lands and does not require much care ${ }^{3}$. At present, aonla is being cultivated in an area of about 91,000 ha with an annual production of 0.989 million tonnes in the country ${ }^{4}$. Fruits of aonla are a rich source of vitamin C (400-600 mg/100 g), pectin $(2.25 \%-11.19 \%)^{5}$ and polyphenols $(24.61 \%-31.12 \%)^{6}$ which prevent oxidation of vitamin $\mathrm{C}$, and are being used in the Ayurvedic and Unani systems of medicine ${ }^{7}$. Aonla fruits are not consumed as fresh because of their sour and

\footnotetext{
*For correspondence. (e-mail: manojmahawar362@gmail.com)
}

astringent taste. The nutritive and remedial worth offers great potential for its processing into many valorized products like candy, dried powder, juice, preserve, pickle, ready-to-serve beverages, shreds, etc. ${ }^{8}$.

Owing to its good keeping quality, aonla candy has considerable demand in domestic as well as international market. Further, to strengthen its demand, retention of quality attributes and its storability are of considerable importance. Aonla candy is usually prepared by dipping in sugar syrup followed by cabinet drying, which results in loss of nutritional quality. Hence, there is need to fortify it with nutrition-rich sweeteners. Therefore, use of pomegranate juice in the preparation of aonla candy will increase its nutritional value as well as colour acceptability. Pomegranates are rich in polyhenols and have high antioxidant capacity which makes it nutritionally important for human health ${ }^{9}$. Pomegranate juice is highly acceptable and makes a delicious drink. It contains sugar (15.2-20.5\%), acidity (0.52-1.6), pectin (0.05-1.2\%), ascorbic acid (3.3-6.4 mg/100 g) and many minerals ${ }^{7}$.

Significant studies have been reported regarding the formulation of aonla candy, but there is none involving preparation of aonla candy by impregnation of pomegranate juice to improve the colour and nutritional quality of the end product. Therefore, the present study was undertaken to assess the nutritional quality of aonla candy fortified with pomegranate juice using response surface methodology (RSM).

Uniformly ripened and mature aonla fruits of cultivar Chakaiya and fresh pomegranate fruits of cultivar Mridula were harvested during January 2017 from the experimental orchard of ICAR-Central Institute of Post-Harvest Engineering and Technology, Abohar, Punjab, India. Fresh aonla fruits of uniform size were selected and washed with tap water. Salt, sugar and other chemicals were procured from the local market of Abohar. Pomegranate fruit was cut in half using stainless-steel knife and arils were removed manually. Arils used to prepare juice were placed into a juice extractor. The washed aonla fruits were blanched in hot water at a temperature of $85^{\circ} \mathrm{C}-90^{\circ} \mathrm{C}$ for $8-10 \mathrm{~min}$ followed by dipping in cold water. Segments were separated manually and dipped in $2.5 \%$ salt solution for $24 \mathrm{~h}$ at ambient temperature. Thereafter, the segments were taken out and dipped in different concentrations of sugar syrup $\left(0,30\right.$ and $60^{\circ}$ Brix $\left.\left({ }^{\circ} \mathrm{B}\right)\right)$ by maintaining the ratio of sugar syrup to aonla segments as $2: 1(\mathrm{v} / \mathrm{w})$. Next the sample was dipped in pomegranate juice for different time periods (30, 60 and $90 \mathrm{~min}$ ). The pomegranate juice was allowed to drain for 2 min followed by drying of aonla segments at various temperatures $\left(50^{\circ} \mathrm{C}, 60^{\circ} \mathrm{C}\right.$ and $\left.70^{\circ} \mathrm{C}\right)$ till the moisture content of candy reached $11-12 \%$ according to the experimental design. It was then packed in airtight plastic jars till the further evaluation.

RSM (Design expert version 9.0, USA) was adopted for optimization of sugar syrup concentration (SSC), time 


\section{RESEARCH COMMUNICATIONS}

of dipping (TD) and drying temperature (DT) for the preparation of pomegranate juice-fortified aonla candy. Preliminary trials were conducted in order to identify the range of selected variables (Table 1). The Box-Behnken design was utilized for the experimental design using the range of process variables, i.e. SSC $\left(0,30\right.$ and $\left.60^{\circ} \mathrm{B}\right)$, TD (30, 60 and $90 \mathrm{~min})$ and DT $\left(50^{\circ} \mathrm{C}, 60^{\circ} \mathrm{C}\right.$ and $\left.70^{\circ} \mathrm{C}\right)$ (Table 2).

The data obtained for individual responses were fitted in a polynomial equation as given below

$$
Y_{k}=\beta_{0}+\sum_{i=1}^{M} \beta_{i} X_{\mathrm{i}}+\sum_{i=1}^{n} \sum_{j=1}^{n} \beta_{i j} X_{\mathrm{i}} X_{\mathrm{j}}+\sum_{i=1}^{m} \beta_{i i} X_{\mathrm{i}}^{2},
$$

where $Y_{k}$ is the response variable, $\beta_{0}$ the value of the fitted response at the centre point of the design, i.e. $(0,0)$, and $\beta_{i}, \beta_{i j}, \beta_{i i}$ are the linear, quadratic and interactive regression coefficients respectively. $X_{\mathrm{i}}$ and $X_{\mathrm{j}}$ are the coded independent variables. Corresponding magnitude of the coefficients in the equation represents the effect of a particular parameter on the response.

Standard procedures were employed to determine moisture content (Method 925.10) ${ }^{10}$ using a hot-air oven, titratable acidity (Method 942.15) ${ }^{10}$ and ascorbic acid content (Method 967.21) ${ }^{10}$. Total soluble solids (TSS) were measured using a hand-held refractometer $(\mathrm{M} / \mathrm{s}$ Erma, Japan).

Table 1. Coded and actual levels of process variables

\begin{tabular}{lccc}
\hline & \multicolumn{3}{c}{ Coded and actual levels } \\
\cline { 2 - 4 } Independent variables & -1 & 0 & 1 \\
\hline Sugar syrup concentration (SSC), ${ }^{\circ} \mathrm{B}\left(X_{1}\right)$ & 0 & 30 & 60 \\
Time of dipping (TD), $\min \left(X_{2}\right)$ & 30 & 60 & 90 \\
Drying temperature (DT), ${ }^{\circ} \mathrm{C}\left(X_{3}\right)$ & 50 & 60 & 70 \\
\hline
\end{tabular}

Table 2. Three level Box-Behnken experimental design with coded and actual values (coded values are given in parenthesis)

\begin{tabular}{ccrr}
\hline Run & SSC $\left({ }^{\circ} \mathrm{B}\right)$ & TD $(\min )$ & DT $\left({ }^{\circ} \mathrm{C}\right)$ \\
\hline 1 & $0(-1)$ & $30(-1)$ & $60(0)$ \\
2 & $30(-1)$ & $60(0)$ \\
3 & $60(1)$ & $90(1)$ & $60(0)$ \\
4 & $0(-1)$ & $90(1)$ & $60(0)$ \\
5 & $60(1)$ & $60(0)$ & $50(-1)$ \\
6 & $60(0)$ & $50(-1)$ \\
7 & $0(-1)$ & $60(0)$ & $70(1)$ \\
8 & $60(1)$ & $60(0)$ & $70(1)$ \\
9 & $0(-1)$ & $30(-1)$ & $50(-1)$ \\
10 & $60(1)$ & $90(1)$ & $50(-1)$ \\
11 & $30(0)$ & $30(-1)$ & $70(1)$ \\
12 & $30(0)$ & $90(1)$ & $70(1)$ \\
13 & $30(0)$ & $60(0)$ & $60(0)$ \\
14 & $30(0)$ & $60(0)$ & $60(0)$ \\
15 & $30(0)$ & $60(0)$ & $60(0)$ \\
16 & $30(0)$ & $60(0)$ & $60(0)$ \\
17 & $30(0)$ & $60(0)$ & $60(0)$ \\
\hline
\end{tabular}

The fortified candy samples were organoleptically evaluated by a panel of 20 semi-trained people (age 30 to 40 years) using a nine-point hedonic scale according to the method of Ranganna ${ }^{11}$.

RSM was adopted for design of the experiment, while data analysis and regression analysis were used for model fitting $^{12}$. Optimization of multiple responses was achieved by numerical optimization technique, where goals were assigned to the variables (within range) and responses (maximize, minimize, target, within range, none) ${ }^{13}$. Among the solutions obtained, the one having maximum desirability was chosen as the optimal process condition ${ }^{12}$. The

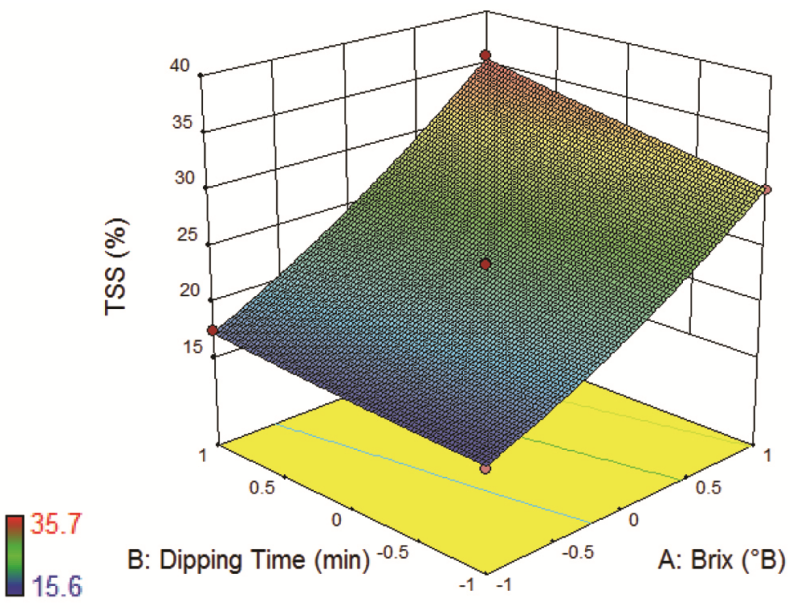

Figure 1. Response surface curve showing variation of total soluble solids (TSS) as a function of time of dipping (TD) and sugar syrup concentration (SSC).

Table 3. Analysis of variance and coefficient estimates of selected quadratic models for responses

\begin{tabular}{|c|c|c|c|c|}
\hline Parameter & $\begin{array}{l}\mathrm{TSS} \\
\left({ }^{\circ} \mathrm{B}\right)\end{array}$ & $\begin{array}{c}\text { AA } \\
(\mathrm{mg} / 100 \mathrm{~g})\end{array}$ & TA $(\%)$ & OAA \\
\hline Intercept & 23.42 & 171.98 & 2.678 & 7.46 \\
\hline$X_{1}$ & $8.162 * *$ & $27.375^{* *}$ & $-1.255^{* *}$ & $0.625 * *$ \\
\hline$X_{2}$ & $1.637 * *$ & $20.025 * *$ & -0.241 & $0.075^{* *}$ \\
\hline$X_{3}$ & -0.05 & $-1.70 * *$ & $-0.411 * *$ & $-1.1 \mathrm{E}-16$ \\
\hline$X_{1} X_{2}$ & $0.95 * *$ & $-29.775 * *$ & $0.617 * *$ & $-6.7 \mathrm{E}-16$ \\
\hline$X_{1} X_{3}$ & -0.075 & 11.075 & -0.127 & $2.96 \mathrm{E}-18$ \\
\hline$X_{2} X_{3}$ & -0.125 & $-28.975 * *$ & 0.05 & 0.05 \\
\hline$X_{1}^{2}$ & $1.14 * *$ & -16.277 & $0.783 * *$ & $-0.405^{* *}$ \\
\hline$X_{2}^{2}$ & 0.14 & 9.222 & -0.134 & 0.045 \\
\hline$X_{3}^{2}$ & -0.235 & $-43.727 * *$ & $0.411 * *$ & 0.195 \\
\hline \multicolumn{5}{|l|}{ ANOVA } \\
\hline$R^{2}$ & 0.99 & 0.90 & 0.96 & 0.90 \\
\hline Model $F$-value & $679.49 * *$ & $7.42 * *$ & $18.57 * *$ & $7.04 * *$ \\
\hline Lack of fit ( $P$ value $)$ & 0.09 & 0.84 & 0.35 & 0.61 \\
\hline $\mathrm{CV}(\%)$ & 1.27 & 13.39 & 10.75 & 3.40 \\
\hline
\end{tabular}

$P$ value indicates the level of significance. ${ }^{* *}$ refers to significance level of $5 \%$. Intercept refers to the constant for linear and quadratic model. $X_{1}$, Sugar syrup concentration; $X_{2}$, Time of dipping; $X_{3}$, Drying temperature; TSS, Total soluble solids; AA, Ascorbic acid; TA, Titratable acidity; OAA, Overall acceptability. $X_{1} X_{2}, X_{1} X_{3}$ and $X_{2} X_{3}$ represent interaction effects of process variables. $X_{1}^{2}, X_{2}^{2}$ and $X_{3}^{2}$ represent quadratic effects of process variables. 

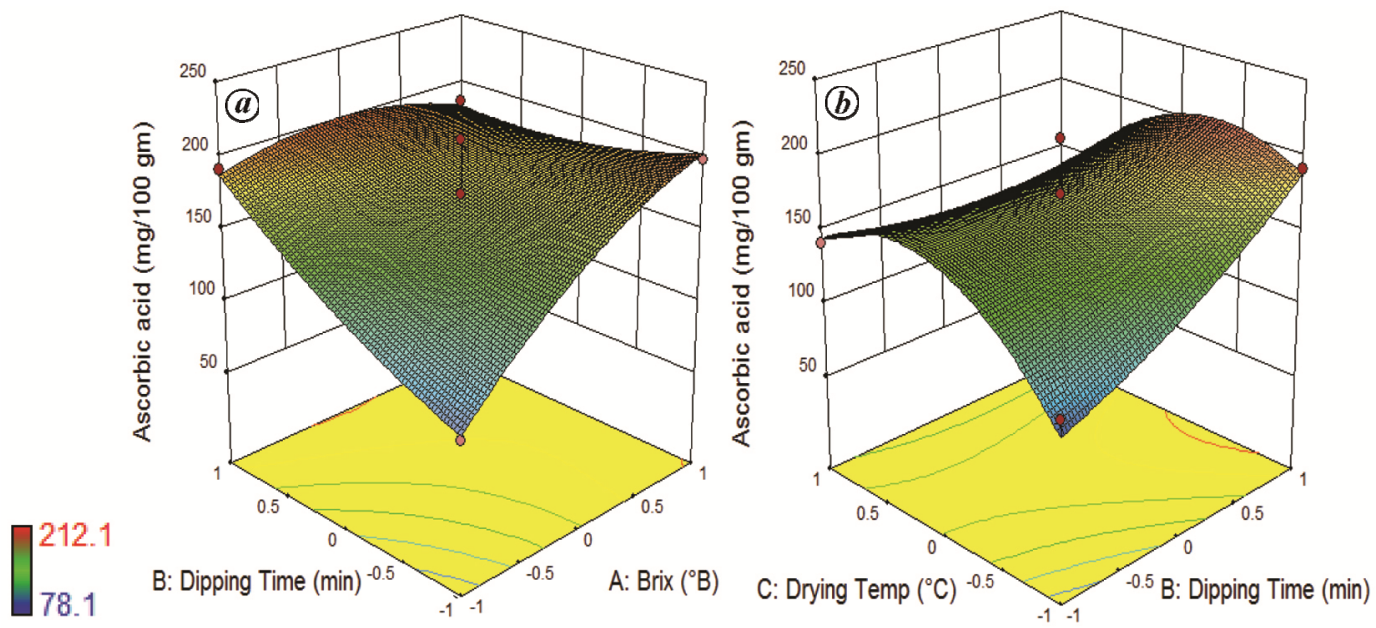

Figure 2. Response surface curve showing variation in ascorbic acid (AA) as a function (a) SSC and TD, and (b) TD and drying temperature (DT).

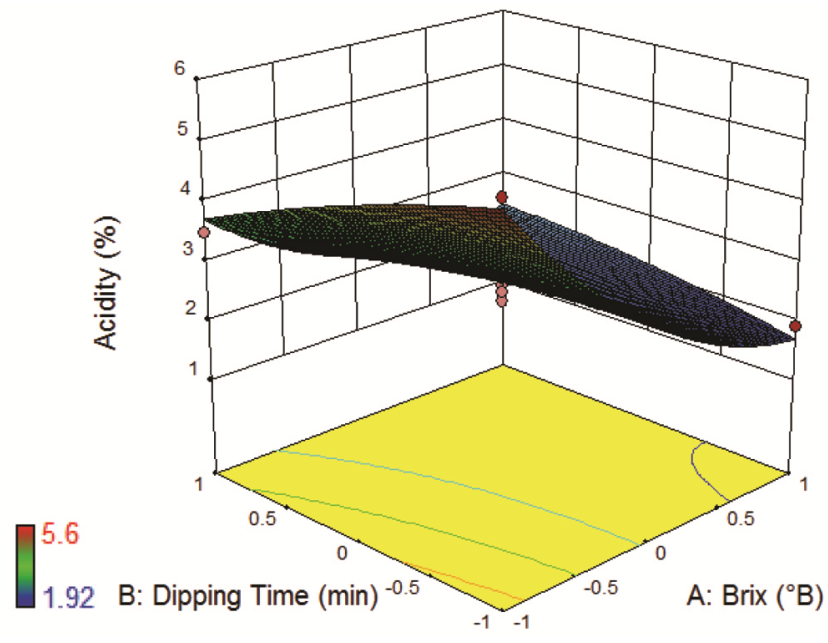

Figure 3. Response surface plot showing the effect of SSC and TD on titratable acidity (TA).

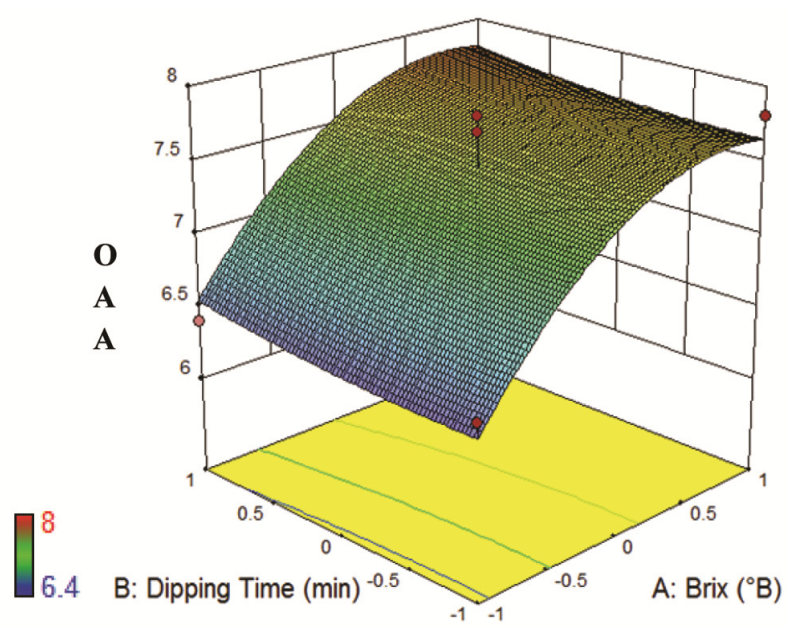

Figure 4. Response surface curve showing the variation in overall acceptability (OAA) with respect to SSC and TD. three-dimensional contour graphs were plotted representing the effect of two variables on a particular response.

Table 3 presents the regression coefficients (linear, interactive, quadratic) pertaining to various responses along with their respective levels of significance. Higher coefficient of determination $\left(R^{2}>0.90\right)$, and model $F$-value substantiated that the models for all responses were significant $(P<0.01)$. Lack of fit of all the models was not significant, which indicates that the models were correlated well with the measured data.

TSS of the pomegranate juice fortified candy was found to be in the range 15.6-35.7\%. The effect of linear terms of SSC and TD, interaction effect of SSC and TD and quadratic effect of SSC were significant (Table 3). The increase in SSC from 0 to $30^{\circ} \mathrm{B}$ led to increase in TSS of fortified candy. However, further increase in SSC (beyond $30^{\circ} \mathrm{B}$ ) showed positive quadratic effect on TSS. Positive linear effect of TD in pomegranate juice was observed from 30 to 90 min of dipping on TSS (Figure 1).

The linear positive terms of SSC and TD indicated that AA increased with increase in SSC and TD in pomegranate juice, whereas decrease in AA was observed with increase in DT (Table 3). The presence of negative interaction terms of SSC and TD as well as TD and DT confirmed that an increase in their levels led to reduced values of AA. Also, AA content of pomegranate juicefortified aonla candy ranged from 78.1 to $212.1 \mathrm{mg} / 100 \mathrm{~g}$ (Figure 2). The obtained models were found appropriate in predicting the responses, as also evident from the nonsignificant values of lack of fit. The developed model for ascorbic acid had $R^{2}=0.905$, which indicates that it adequately explains $90.5 \%$ of total variation.

TA of the pomegranate juice fortified candy was found to be $1.92-5.6 \%$ (Figure 3 ). Table 3 indicates that TA decreased with increase in SSC, TD and DT. The positive regression coefficients of interactive terms among SSC 


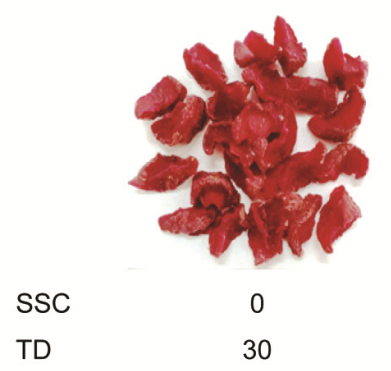

TD

DT

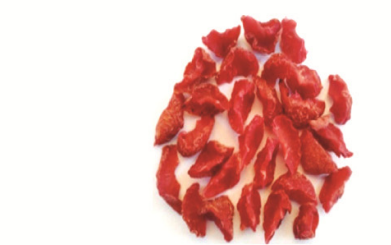

SSC

TD

DT

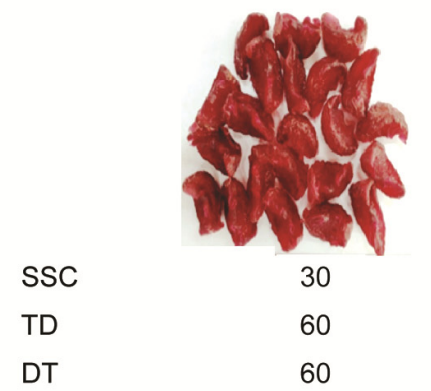

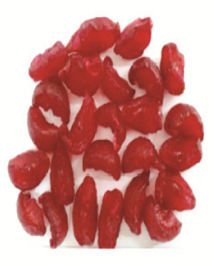

60

30

60

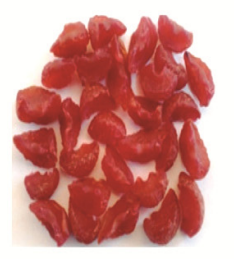

60

60

70

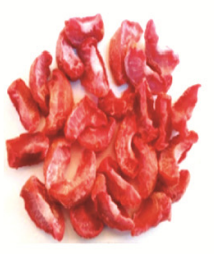

0

90

60

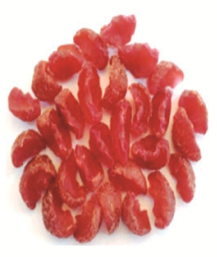

30

30

50

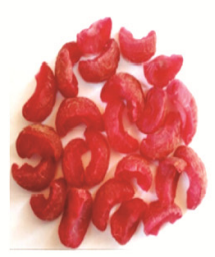

60

90

60

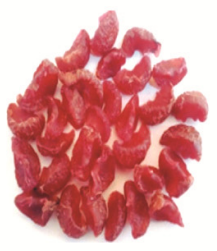

30

90

50

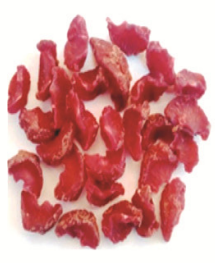

0

60

50

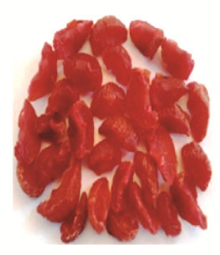

30

30

70

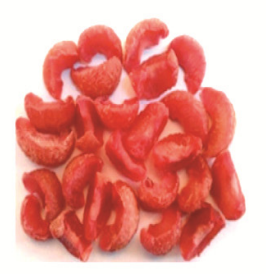

30

60

60

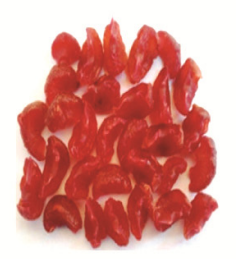

60

60

50

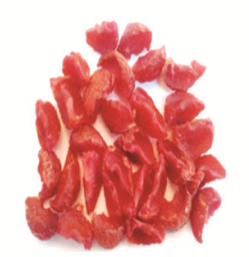

30

90

70

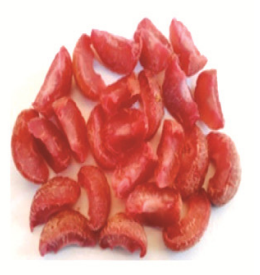

30

60

60

Figure 5. Fortified aonla-pomegranate candy prepared using different process conditions.

and TD showed that they were linearly associated with TA of fortified candy. Similarly, positive linear trend was observed with quadratic coefficients of SSC and DT in relation to TA. The second-order polynomial equation after removing non-significant variables is presented below

$$
\begin{aligned}
\text { TA }(\%)= & 2.678-1.255 X_{1}-0.411 X_{2}+0.617 X_{3} \\
& +0.783 X_{1}^{2}+0.411 X_{3}^{2}\left(R^{2}=0.96\right) .
\end{aligned}
$$

The linear positive terms of SSC and TD were observed from 0 to $30^{\circ} \mathrm{B}$ and from 30 to 90 min respectively, which resulted in increase in OAA of fortified candy with increase in SSC and TD. The negative quadratic coefficients of SSC suggested that further increment in SSC value beyond $30^{\circ} \mathrm{B}$ resulted in lower OAA score (Table 3 ). The OAA score of aonla candy ranged from 6.4 to 8 (Figure 4). The highest value for OAA (8.00) was observed at $60^{\circ} \mathrm{B}$ of SSC, $60 \mathrm{~min}$ of TD and $50^{\circ} \mathrm{C}$ of DT. Figure 5 is a pictorial representation of fortified candy prepared using different process conditions.
Optimization was carried out by applying the following constraints: maximization of TSS, AA, OAA and minimization of TA. Optimum conditions obtained for production of the desired candy were SSC of $60^{\circ} \mathrm{B}$, DT of $30 \mathrm{~min}$ and $\mathrm{DT}$ of $66.85^{\circ} \mathrm{C}-70^{\circ} \mathrm{C}$. The corresponding values of responses were: TSS of $30.16^{\circ} \mathrm{B}$, AA $207.79 \mathrm{mg} / 100 \mathrm{~g}$, TA $1.48 \%$ and OAA 7.71 . The observed values of AA were on par with the sugar-free sucralose aonla candy, whereas TA and OAA values were found to be higher ${ }^{14}$. The high value of TA may be due to the acidic nature of pomegranate juice. Vishen et al. ${ }^{15}$ prepared flavoured aonla candy using ginger (5\%) with TSS $70.32^{\circ} \mathrm{B}$, acidity $0.59 \%$, AA $111.75 \mathrm{mg} / 100 \mathrm{~g}$ and OAA 8.78. In another study, aonla candy having TSS $72^{\circ} \mathrm{B}$, acidity $0.51 \%$, AA $132.80 \mathrm{mg} / 100 \mathrm{~g}$ and OAA 8.02 was selected for fortification with ginger $(2 \%)$ extract and the organoleptic properties, viz. flavour (8.75), colour $(8.55)$ and astringency $(8.82)$ were recorded ${ }^{16}$.

Pomegranate juice-fortified aonla candy was prepared in this study by optimizing the levels of sugar syrup, dipping time and drying temperature. Statistical analysis 
substantiated the suitability of fitted response models and satisfactorily predicted the variation in processing parameters. The optimum process conditions for preparation of novel aonla candy were SSC $60^{\circ} \mathrm{B}$, TD $30 \mathrm{~min}$ and DT $70^{\circ} \mathrm{C}$. The study confirms the feasibility of development of this innovative product with a greater nutritive value, which also may attract more attention in the market.

1. Singh, I. S. and Pathak, R. K., Evaluation of amla varieties for processing. Acta Hortic., 1987, 208, 173-177.

2. Mahawar, M. K., Jalgaonkar, K. R., Kadam, D. M. and Chavan, P., Entrepreneurial skill development through aonla processing in Punjab, India. Food Sci. Nutr. Stud., 2017, 1(1), 23-30.

3. Singh, S., Singh, A. K. and Joshi, H. K., Standardization of maturity indices in Indian gooseberry (Emblica officinalis G.) under semi-arid conditions of Gujarat. Indian J. Agric. Sci., 2006, 76, 591-595.

4. Anon., Department of Agriculture and Co-operation, Government of India, 2017; www.indiastat.com (accessed on 20 August 2019).

5. Kumari, P. and Khatkar, B. S., Physico-chemical properties and nutritional composition of aonla (Emblica officinalis G.) varieties. Int. Food Res. J., 2015, 22(6), 2358-2363.

6. Tewari, R., Kumar, V. and Sharma, H. K., Physical and chemical characteristics of different cultivars of Indian gooseberry (Emblica officinalis G.). J. Food Sci. Technol., 2019, 56(3), 1641-1648.

7. Gopalan, C., Ramasastri, B. V. and Balasubramaninan, S. C., Nutritive value of Indian foods. National Institute of Nutrition, ICMR, Hyderabad, 1995, pp. 45-94.

8. Tandon, D. K., Yadav, R. C., Sood, S., Kumar, S. and Dikshit, A., Effect of blanching and lye peeling on the quality of aonla candy. Indian Food Packer, 2003, 57(6), 147-152.

9. Gil, M. I., Tomas-Berberan, A., Hess-Pierce, B., Holcroft, D. M. and Kader, A. A., Antioxidant activity of pomegranate juice and its relationship with phenolic composition and processing. $J$. Agric. Food Chem., 2000, 48, 4581-4589.

10. AOAC, Official method of analysis of the Association of Official Analytical Chemists, Washington, DC, USA, 1990, 15th edn.

11. Ranganna, S., Handbook of Analysis and Quality Control of Fruits and Vegetable Products, Tata McGraw-Hill, New Delhi, 1986.

12. Bibwe, B., Mishra, I. M., Kar, A., Samuel, D. V. K. and Iquebal, M. A., Optimization of oil loading and starch-protein ratio for encapsulation of flaxseed oil using response surface methodology. J. Agric. Eng., 2019, 56(2), 80-90.

13. Mahawar, M. K., Jalgaonkar, K., Bibwe, B., Kulkarni, T., Bhushan, B. and Meena, V. S., Optimization of mixed aonlaguava fruit bar using response surface methodology. Nutr. Food Sci., 2018, 48(4), 621-630.

14. Ingle, M., Patil, J. and Nawkar, R., Nutritional evaluation of sugar free aonla candy. Asian J. Dairy Food Res., 2016, 35(4), 323-326.

15. Vishen, G. S., Pathak, S., Mishra, K. K., Shukla, A. K. and Singh, N. P., Studies on changes during storage of flavored aonla (Emblica officinalis G.) candy cv. Chakaiya in different packaging containers. J. Pharmacogn. Phytochem., 2017, 6(6), 2273-2277.

16. Dwivedi, S. K. and Pandey, A., Development of protocol for preparation and preservation of ginger flavored aonla candy for nutritional and biochemical evaluation. Pharma Innov. J., 2017, 6(11), 78-83.

Received 10 August 2018; revised accepted 5 September 2019

doi: $10.18520 / \mathrm{cs} / \mathrm{v} 118 / \mathrm{i} 1 / 114-118$

\section{Potential application of yellow gypsum from LD slag as a soil conditioner}

\author{
Shrenivas Ashrit ${ }^{1, *}$, Ravikrishna V. Chatti ${ }^{1}$, \\ S. Sarkar ${ }^{1}$, R. Venugopal $^{2}$ and G. Udayabhanu ${ }^{3}$ \\ ${ }^{1}$ R\&D Department, Tata Steel Limited, Jamshedpur 831 007, India \\ ${ }^{2}$ Department of Fuel, Minerals and Metallurgical Engineering, and \\ ${ }^{3}$ Applied Chemistry Department, Indian Institute of Technology \\ (Indian School of Mines), Dhanbad 826 004, India
}

In the present study, ICP-AES and ICP-MS techniques were used to analyse and validate the content of heavy and trace elements in yellow gypsum samples produced by a chemical process from a solid waste generated at an integrated steel plant. The present study tries to demonstrate that the content of heavy metals like lead, mercury and arsenic in yellow gypsum is less than the toxicity characteristic leaching procedure (TCLP) norms set for a comparable industrial by-product phospho-gypsum. This study also concludes that yellow gypsum contains some elements (copper, boron, etc.) in traces, apart from heavy metals which are beneficial to plants as micronutrients.

Keywords: Heavy metals, ICP-MS, ICP-AES, trace elements, yellow gypsum.

QUANTIFICATION of hazardous, heavy and trace elements in products, particularly produced from industrial wastes is very important for their possible applications in various sectors especially in agriculture. Efforts are being made worldwide by scientists for economic utilization of steel plant wastes. One such effort is the production of high purity iron and $\mathrm{CaO}$-based sorbent using acetic acid by Tian et al. ${ }^{1}$ and secondly production of yellow gypsum and gypsum by Ashrit et al..$^{2,3}$.

Yellow gypsum produced from the Ling-Donawitz (LD) slag fines has very good plant nutrient value in terms of calcium, iron, phosphorus, magnesium and silicon, apart from various other trace elements beneficial for plants like boron, copper, manganese, etc. Environment protection agency (EPA), USA has also studied the quantity of contaminants mainly heavy metals and nonnutrient metals present in various fertilizers as a part of information gathering initiative $e^{4}$. Such studies are essential as these contaminants enter the food chain through plants and vegetables. To quantify the heavy and trace elements present in yellow gypsum, sample preparation is an important step of the analysis. Lithium metaborate fusion dissolution method and open acid digestion with different acid combinations followed by inductively coupled plasma-mass spectroscopy (ICP-MS) analysis were discussed by Roy et al. ${ }^{5}$. Similarly, Cremer and Schlocker $^{6}$ had discussed about lithium borate fusion

*For correspondence. (e-mail: shrenivas@tatasteel.com) 